\title{
The Impact of Migration Processes on the National Security System of Russia
}

\author{
Marina V. Vinogradova \\ Olga S. Kulyamina \\ Victoriy A. Koroleva
}

Russian State Social University, Russian Federation

\author{
Anna A. Larionova \\ Moscow State University of Design and Technology, Russian Federation \\ Email: annla@list.ru
}

\section{Doi:10.5901/mjss.2015.v6n3s5p161}

\section{Abstract}

\begin{abstract}
The aim of this research is the rationale for the formation of complex parameters, criteria and indicators reflecting the relationship between migration, socio-economic processes and the national security. The subject of study is the nature of the impact of migration on the national security system and their interaction with social and economic development of the state. The research methods used are abstraction techniques and comparative analysis, method of data analysis and systematization, structural-descriptive method. The result of this study is a new approach to the construction of the evaluation system of migration processes and their influence on the national security, which can be used in the development of strategic documents in the field of migration, socio-economic development, and the national security. The authors emphasized the need for a more detailed approach to the impact of migration on the various elements of national security. In addition, the discrepancy of the assessment tools used with the objectives of the national security and migration policy are defined. The indicators can only be used to examine the status and possible developments of the situation, however, cannot be used to assess the occurrence of possible threats and negative calls when changing migration situation and the influence of various external and internal factors. The authors plan to further develop the investigated problems in the development and validation of specific parameters, criteria and indicators for inclusion in the proposed complex.
\end{abstract}

Keywords: national security, migration, migration policy, social and economic conditions

\section{Introduction}

Nowadays, national security is generally regarded as a rather complex phenomenon with many aspects. Multidimensionality of the "national security" concept requires a special approach to its study and development of measures to secure it. The primary aim of the national security system is the formation and maintenance of internal and external conditions favorable to the realization of the most important areas of national security, on which the sustainable socio-economic development is achieved. Among the threats to national security, scholars include the dynamic development of migration processes that cause the strengthening of inter-ethnic tension.

National security system involves ensuring the protection of the vital interests of the individual, society and the state in different spheres of internal and external threats (Dovgopolov, 2009). It is formed by combining three interdependent levels: citizen security, public safety and security of the state as a whole. Citizen security is ensured by the compliance with the constitutional rights and freedoms; improving the quality and standard of living; providing and supporting the physical, spiritual and intellectual development. Public safety is the protection of the material, spiritual and cultural values, and augmenting their enrichment in guaranteed freedom of social groups and protection from actions leading to a split in society. Security of the state (i.e. national security) is to protect from external and internal threats, providing defense capability, protection of sovereignty, constitutional order, territorial integrity, political and economic stability, the quality of life of citizens of the state (Stepanov, 2014).

The above-mentioned levels of the national security, in turn, include the security of the state, public, international, environmental, economic, spiritual and moral, technological, energy, informational, and are influenced by many different factors, such as political, economic, natural, technological, social, etc. (Kurgan \& Anfimova, 2013). Multidimensionality of 
the concept of 'national security', respectively, and requires a special approach to its study and development of measures to secure it.

Globalization processes of socio-economic development, international political and economic relations, create the preconditions for the formation of new threats and risks for the development of the individual, society and the state as a whole. That is why today there is no issues and problems in the field of security, which can be ignored. First of all, national security is based on its relationship and interdependence of socio-economic development (Mirilovic, 2009). The same can be attributed to Russia - the state of the national security of the Russian Federation is directly dependent on its socio-economic development. That is why the primary purpose of the national security system is the formation and maintenance of internal and external conditions favorable to the realization of the most important areas of national security, which, inter alia, include the implementation of sustainable socio-economic development.

Ensuring the effective functioning of the national security system is achieved through the resolution of a set of tasks, which include (Kurgan \& Anfimova, 2013):

- Sovereignty;

- Ensuring the constitutional rights and freedoms of the individual;

- Maintaining the territorial integrity and defense capability of border areas;

- Identification, forecasting and measures to combat crime, ensuring a comfortable and safe living of the citizens of the state;

- Development and implementation of programs to combat terrorism; international cooperation in the fight against transnational terrorism and crime, as well as control on export / import of goods, control of weapons of mass destruction;

- Implementation of measures to combat illegal migration;

- Implementation of measures for the efficient and rational use and reproduction of natural resources; promote the development and implementation of safe production technologies; ensuring information security.

In turn, the results of national security are assessed via a certain set of criteria indicators, including the level of unemployment; consumer price inflation; amount of public debt relative to gross domestic product; availability and the effiecient use of resources in health, culture, education and science sectors; the rate of inflation; level of equipment and a variety of military equipment, providing defenses; human resources; decile ratio; the extent of the shadow economy. Hence, there is a discrepancy between the formulated objectives and criteria used. Thus, the implementation of the tasks of the sovereignty, territorial integrity and the maintenance of defense of border areas can be roughly estimated in terms of the level and a variety of military equipment, providing defenses. However, the relationship between the achievement of certain results and the criteria used is also unclear.

Other objectives can be traced via indirect links. For example, it is clear that ensuring the constitutional rights and freedoms of the individual includes the provision of resources for health, culture, education and science sectors, the availability of labor, characterized by unemployment, and other parameters. However, because there is no unity of views on the understanding of national security, each of its components is considered separately from each other, there is no specific evaluation system to ensure it. In particular, national security involves the implementation of measures to combat illegal migration. In this case, there is no formalized effective approaches to assess the impact of migration on the national security system.

\section{Literature Review}

Migration processes are an important factor of socio-economic, socio-cultural and demographic development, which in turn largely determines the state of national security at all levels - citizen security, public safety and security of the state as a whole (Torrado \& Lylian, 2008). Migration processes in Russia often have a destabilizing effect, turning into crises, preventing the normal functioning of the state, social groups and individuals. Uncontrolled and illegal migration is a threat to sustainable socio-economic development of Russia, which in turn has an impact on the national security system of Russia. Such complex and controversial issue as migration is of interest for many researchers. One of the interesting questions is review migration in the context of its impact on national security. A number of authors in Russia and abroad raised this issue, the number of publications is growing, as the processes and problems become more complex. The search engine of the Russian Science Citation Index displays more than 20 thousand references with the words 'security' and 'migration' used as a keyword. This relationship is most often viewed through economic, internal, public safety (Vasilyeva, 2014), a direct effect of migration on national security (Dovgopolov, 2009), as well as migration in correlation with security (Vdovina, 2011). 
Changing conditions of socio-political, socio-economic, socio-cultural reality put forward new requirements for the study of migration processes. It is necessary to modify the scientific approach to understanding the role of migration and the formation of research areas of migration, including the need to determine the socio-economic parameters of the interaction of migration in to Russia's national security system. As a result of an integrated approach to the understanding of correlation between migration and national security system can be the defined conditions for sustainable socioeconomic development of the country.

Issues of migration have drawn much attention in the scientific research and practice. Journalists, politicians, lawyers, and other specialists either do not neglect this problem. In general, the problems of migration are addressed from the sociological perspective of this phenomenon (Caviedes, 2006; Adamson, 2006). Detail attention have the problems of the linkages between migration and socio-political situations; problems of mobility and adaptation of migrants to other social environment, including the analysis of the factors that determine the course of adaptation and socialization of foreign nationals; research on the specificity of tolerance and conflicts formation in the context of interaction of migrants with the social communities of the host country; regional patterns of migration are considered (see Vasilyeva, 2014). For example, Yudina (2007) defines a separate field of study - the sociology of migration, the subject of which are the dynamics of the social relations of displaced persons within the old and the new society.

Another line of research on migration and the national security threats being formed in this behalf relate to the legal aspects. Introduced the concept of migration security that involves issues of compliance with the interests of the host country and the interests of migrant workers in the implementation of migration policy and strict compliance with the migration laws. Thus, migration public is considered as safety-legal institution that protects the foundations of legal migration, human rights and freedoms, sustainable migration order (Kurgan \& Anfimova, 2013).

Changing conditions of socio-political, socio-economic, socio-cultural reality put forward new requirements for the study of migration processes, which become an important factor of socio-economic, socio-cultural and demographic development of the state and society; it acquires the features of mass phenomena, while Russia is not an exception. Studies in the field of national security, migration theory and their inter-relationship suggest the need for the formation of complex parameters, criteria and indicators that would reflect the existing direct and indirect links.

\section{Research Methodology}

Uptodate, a lot of research was held and a significant material on the application of various techniques to evaluate the impact of migration on the significant components of national security is accumulated. In particular, this applies to economic security (Vakulenko \& Tsimailo, 2011). European researchers are particularly interested in the issues of international migration generated by the new humanitarian crises (Adamson, 2006; Swing, 2014), while these problems become only worse over the years. Many studies are dedicated to the impact of migration on the labor market structure of the industry (Caviedes, 2006) and the most important political issues of migration (Collet, 2014). The studies were conducted on the relationship of social media, being the popular tool with regard to migration (McGregor \& Siegel, 2013).

However, the available literature pays not enough attention to the comprehensive assessment of migration processes from the point of view of national security and sustainable socio-economic development. A number of topical issues, such as the relation of migration with the national security system, particularities of its provision and regulation of migration processes are not well understood in this context. Modification are required to the scientific approach of understanding the role of migration and the formation of research areas of migration processes on the basis of the socioeconomic parameters of the correlation of migration processes with the system of national security. Only through an integrated approach towards understanding the process of correlation between the migration and national security system can be defined the conditions for sustainable socio-economic development of the country.

Considering only the theoretical foundations of the national security in relation to the migration process is not sufficient to draw conclusions about the significant impact that migration has on national security. Therefore, based on the study of migration processes data on the changes in migration policy taking place, the research on the problems of criminalization, employment, migration, dynamics of the data on registration of foreign citizens in the Russian Federation, the authors can suggest that all of the information available it is not enough. Since the accumulated information is describing only the changes in migration processes, while one cannot see their impact not only on national security, as this influence is indirect, but also on the social and economic processes, which have to be proven. Therefore, the study on the influence of migration on national security was based on the use of methods of structuring and comparing data over time (not less than three years), content analysis, a systematic approach and data consolidation. Study of the problems of influence of the migration processes on the national security system was carried out using the information database of official statistics (Rosstat, 2015; FMS, 2015), data published in the press (Vzglyad, 2015; Rossiysk, 2015) 
and a review of news agencies (Rosbalt, 2015).

\section{Results and Discussion}

Net migration in the Russian Federation according to the Federal State Statistics Service (FSSS) has increased from 2004 to 2013 by 7.2 times (from 41,275 to 295,859 people). Taking into account the movements within Russia, the number of people who changed their permanent residence in 2013 amounted to 4014.6 thousand pers., which is two times more compared to 2004 (1998.3 thousand pers.). Significantly increased the number of foreign nationals, by 304.5\%, who arrived in the Russian Federation for permanent residence (from 119.2 to 482.2 thousand pers.). The dynamics of migration processes has been uneven, as evidently reflected by the growth rate of arrivals, departures and migration growth (Figure 1).

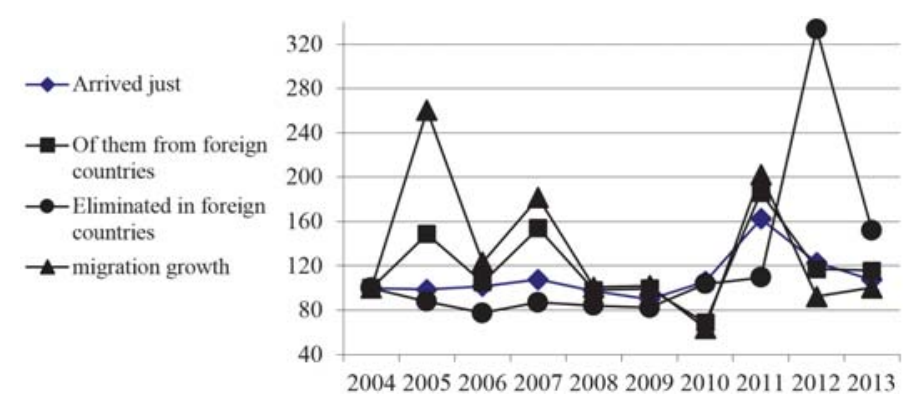

Figure 1. Dynamics of migration in the Russian Federation for the period $2004-2013$, in percent

Source: based on the data of Rosstat http://www.gks.ru/wps/wcm/connect/rosstat_main/rosstat/ru/statistics/population/ demography (january 20, 2015).

It should be noted that this trend line is not related to actual changes in the dynamics of migration flows. Rather, it is a consequence of multiple changes in the rules of admission and registration of foreign citizens, being reflected in a repeatedly changed rules of admission and registration of foreign citizens over the past 10 years. Thus, these changes relate to 2005 (an increase of 260.3\%), in 2007 (an increase of 181.3\%), in 2011, was accepted and ratified the relevant agreement on the legal status of migrant workers and their families in the framework of the Common Economic Space that united Russia, Belarus and Kazakhstan, which caused the leap in migration growth by 202.3\%. (Zayonchkovskaya, 2015).

The study of the FSSS data showed that the main share of the migrants to the Russian Federation are from neighboring countries, in 2013 the share of migrants from the CIS countries amounted to $87.7 \%$. Mass migration from neighboring countries has a negative reaction from the local population because of a different culture and religion, but also because of the fear of losing jobs and a possible increase in the crime rate.

However, the migration gain is not only associated with immigration, but emigration as well. In 2012, there is a noticeable increate in departure of Russian citizens for a permanent residence abroad. In this case, mostly leaving are the citizens with significant skills, which certainly affects the change in qualification level of employment in the country. Although we cannot talk about complete replacement of highly qualified personnel less qualified, the situation in some areas of economic activity has a negative impact on the physical processes and product quality.

A huge impact on the economy and national security of the country have the processes occurring not only in international migration, but also internal migration. The impact of economic, social, demographic, political, ethnic, educational, moral, psychological, military, environmental and other interrelated factors encourages the population to relocate. These factors act simultaneously, forming the direction and magnitude of the migration processes. Migration is an indicator of favorable or unfavorable socio-economic and political situation in a particular region.

Most inter-regional migration is observed in the Central Federal District, as by the number of entrants (61.2\%), and by the number of emigrants (45.3\%), but since arrivals are almost $20 \%$ more, the population of the regions located in this county increases unevenly. It is clear that the main center of attraction in the Central Federal District is the country's capital - Moscow city. Quite active population movements are in the Ural and Northwestern Federal Districts (13.9\% and $10.8 \%$, respectively), and the leaves from the Volga Federal District amount to $24.7 \%$. It should be noted that in some regions the number of arrivals and departures are comparable in scale. For example, in the North-West Federal District 
over the research period arrived 241.6 thousand pers., and 196.9 thousand pers. emigrated. The difference is $22.7 \%$. Approximately the same number is observed in the Central Federal District. However, the majority of regions show the backward dynamics, and in much larger sizes. In the Volga Federal District emigrated 555.8 thousand pers., with the arrivals of just 84.7 thousand pers., which is more than 6 times less. Similar situation can be observed in the North Caucasus Federal District (the difference is more than 4 times). These processes change the structure of the employed population, which creates a threat to the social situation due to the possible occurrence of inter-national, inter-ethnic and religious conflicts, of the economic situation of the regions due to the reduction of regional productivity caused by reducing numbers of working-age population and the inability to make up for the loss in the near future.

Another pattern that can be traced by studying migration processes when compared with the level of unemployment is that the inter-regional migration has a minor correlation. Thus, in the Russian Federation as a whole the unemployment rate by the end of 2013 was at $5.5 \%$, and it tends to decrease. For the period since 2009, it has decreased by $2.8 \%$. The highest unemployment rate is in the North Caucasus Federal District (13.1\%). Approximately the same level of unemployment (6 - 7\%) are in Siberian (7.1\%), Far East (6.7\%), Urals (6.0\%) and South (6.2\%) Federal Districts. The Ural (4.7 times more) and the Far East (2 times more) Federal Districts attract people, while other Federal Districts deflect. This testifies for the different working conditions inherent to these regions.

In general, it is possible to draw conclusions about a very dynamic inter-regional migration occurring within the country. The dynamic development of migration processes contributes to the emergence of new threats to the national security of the Russian Federation, as they often cause increased inter-national and inter-ethnic tension, which leads to the criminalization of society and manifestations of international terrorism. Migration processes in Russia often have a destabilizing effect, turning into crises, preventing the normal functioning of the state, social groups and individuals.

Uncontrolled and illegal migration is a threat to sustainable socio-economic development of Russia, which in turn has an impact on the system to its national security. According to the Federal Migration Service, over the 12 months of 2014 registred $48.5 \%$ of the total number of foreign nationals who entered the Russian Federation (Table 1).

Table 1. Information on the migration situation in the Russian Federation in 2014

\begin{tabular}{|c|c|c|c|c|}
\hline \multirow{2}{*}{ Type of inducators } & \multicolumn{4}{|c|}{ Indicator value } \\
\hline & 2011 & 2012 & 2013 & 2014 \\
\hline Arrivals of foreign nationals, thous.pers. & $13,831.9$ & $15,870.3$ & $17,785.9$ & 17,282 \\
\hline Migration registration, thous.pers. & $6,068.5$ & $6,627.8$ & $7,370.6$ & $8,393.7$ \\
\hline Foreign citizens and stateless persons located in Russia, thous.pers. & & & & 11072,3 \\
\hline Number of administrative responsibility protocols, thous.pcs. & $2,470.6$ & $2,520.7$ & $2,530.4$ & $2,324.9$ \\
\hline Administrative fine, mln.rub. & $5,921.8$ & $6,142.3$ & $6,449.7$ & $6,151.0$ \\
\hline Closeed entry to foreign citizens and stateless persons, pcs. & 64,933 & 88,748 & 459,337 & 644,918 \\
\hline Denied entry to foreign citizens and stateless persons, pers. & & 73,816 & 456,434 & 675,950 \\
\hline Expelled and deported, pers. & 28,585 & 35,115 & 82,413 & 139,034 \\
\hline Issued work permits, pcs. & 1195169 & 1340056 & 1273984 & $1,303,258$ \\
\hline Work permits for highly skilled and qualified personnel, pcs. & 54,861 & 55,848 & 156,655 & 194,925 \\
\hline Issued patents, pcs. & 865,728 & $1,289,204$ & $1,537,323$ & 2386,641 \\
\hline Money sent to budget, mln.rub. & $26,171.3$ & $32,817.3$ & $37,058.8$ & $44,682.3$ \\
\hline including patents, mln.rub. & $3,558.5$ & $6,674.9$ & $8,395.8$ & $18,311.7$ \\
\hline Residence permits and temporary residence permits issued, pcs. & 274,897 & 346,830 & 350,093 & 435,802 \\
\hline Citizenship of the Russian Federation acquired, pers. & 134,983 & 95,737 & 135,788 & 157,791 \\
\hline
\end{tabular}

Source: based on FMS, 2015

In 2013, only in Moscow a half million people from near and far abroad was officially put on record, which is comparable to a population of a large Russian region. At the same time, according to the Moscow police, in 2013 there was a sharp increase in crimes committed by migrants. Foreigners have been caused more than ten thousand crimes, whereas in 2012 less than seven and a half thousand. They account for one in five murder, every second rape, more than half of cases of illegal deprivation of liberty, every third robbery and 40 percent of all brigandages.

In 2014 in Moscow, there was a reduction in the crime rate among migrants by $14 \%$ compared to the same period last year. Reduction in the number of robberies is by $22 \%, 8 \%$ in the number of brigandages. In addition, a $15 \%$ reduction in the number of car thefts compared to the same period last year. The decline in crime is associated primarily with the ongoing active measures to detect and prevent illegal migration. It should be noted, however, that the statistical records 
are maintained according to the number of crimes solved, and the data on the number of crimes committed by migrants, are incomplete. The real crime rate among migrants is much higher than it is shown in official statistics, and can be up to $60-70 \%$ of total offense (Rosbalt, 2015).

Migration processes in Russia are becoming increasingly important primarily due to the segmentation of the labor market, the development of the informal sector (Kulyamina \& Maloletko, 2012), increasing the load on the social infrastructure, the aggravation of international relations, the rising crime rate, low living standard of migrants and their weak integration into the host society (Mirilovic, 2009).

Migration processes have a significant impact on the socio-economic development of both receiver and the transmitter countries. So, by the $5^{\text {th }}$ of February 2015 there were almost 11 million people on the territory of the Russian Federation, of which $67.3 \%$ are men and $32.7 \%$ are women. As many as $75.6 \%$ of all men are in active working age (from 18 to 50 years old), the ration of women is slightly less $-59.4 \%$. Among the purpose of stay the largest share occupies employment (33.9\%) and private reasons (42.2\%), which is likely to be in one way or another related to employment (FMS, 2015). Thus, citizens who are of working age, leaving the country with a purpose of employment, one way or another, affect the changes in the economy of the outgoing state. At the same time, the income received by foreign migrant workers in the form of earnings are being used in the same country only partly, and most of it "leak" abroad. This situation negatively affects the economic security that affects national security in general.

The other side of migration and its impact on Russia's national security is formed due to the illegal processes. Illegal labor immigration has a significant impact on the transformation of the Russian labor market. Several researchers noted the appearance of specific sectors of the migrant labor market. For example, according to the Federal State Statistics Service, the major share (67.6\%) of workers in the Russian Federation is engaged in construction, $13.1 \%$ in agriculture. Other areas of activity include cleaning services (5.5\%), transportation (5.8\%), services of nannies and tutors (1.0\%), and care for the elderly and patients (1.5\%). The rest part is occupied by other services and works.

In regions such as Moscow and St. Petersburg, migrant niches become one of the factors of development, which cannot be effective without the continued existence of these sectors in the economy. It should be noted that the transformation of the labor market under the influence of illegal migration is an ambiguous phenomenon for the economy and national security. On the one hand, the occupation of certain labor niches by migrants makes the economy be dependable on migrants, the opportunities for regulation of the labor market are reduced. On the other hand, the use of low-skilled labor of migrants in not prestigious, from the point of view of Russian specialists, works in economically developed countries makes it possible to improve the terms of education for its citizens, thereby increasing the human capital of the indigenous population (Kasnauskiene \& Vebraite, 2014).

Considering the existing problems of the demographic crisis in the Russian Federation, associated with population decline and aging, attraction of foreign workers is a need for further progressive development of the Russian economy.

Despite the positive aspects associated with the partial fulfillment of the labor force in Russia, migration processes give rise to problems related to national security. Illegal and irregular migration contributes to an increase in crime, increasing the number of administrative offenses committed by foreign nationals. Migrants have a poor command of the Russian language, level of education of migrants decreases, the labor migration increasingly involves young people who have only incomplete or complete secondary education, without the experience of living in the big cities or skills of stay in an urban environment, any culture of behavior in society. Low cultural level of migrants provokes negative attitude to them by local residents. In addition, illegal migration contributes to the deterioration of the epidemiological situation in the host regions.

In order to exclude the negative effects of labor migration, there are fundamental change in the rules of labor migration in the Russian Federation, which entered into force on the $1^{\text {st }}$ of January 2015, repealing the quotas of foreign labor. For the employer, the hiring process of a foreign worker in became much simpler in respect, however, became more complicated to a foreign worker. In order to work legally on the territory of Russia, a foreigner needs to purchase a patent, which in turn requires the provision of a number of documents, such as a migration card, health card, certificate of non-communicable diseases and HIV, a certificate of proficiency in Russian language and the basics of Russian history and culture, as well as to be fingerprinted and photographed. In this case, the migrant obtains far more rights and opportunities to work legally. But the effectiveness of these measures will be revealed over time, as despite the everincreasing number of formally employed workers, the majority of migrants are still working in the informal sector of the economy (Table 2). 
Table 2. Information on the the migration situation in the Russian Federation

\begin{tabular}{lcccc}
\hline \multicolumn{1}{c}{ Indicator } & \multicolumn{2}{c}{ January } & \multicolumn{2}{c}{ February } \\
\cline { 2 - 5 } & 2014 & 2015 & 2014 & 2015 \\
\hline Arrivals of foreign nationals, thous.pers. & $1,797.3$ & $1,745.0$ & $3,140.6$ & $3,258.8$ \\
\hline Migration registration, thous.pers. & 870.9 & 585.4 & $1,770.2$ & $1,457.9$ \\
\hline Foreign citizens and stateless persons located in Russia, thous.pers. & & $10,940.5$ & & $10,950.6$ \\
\hline Number of administrative responsibility protocols, thous.pcs. & 165.8 & 147.8 & 360.0 & 331.7 \\
\hline Administrative fine. mln.rub. & 797.6 & 416.9 & 1562.1 & 1082.9 \\
\hline Closeed entry to foreign citizens and stateless persons, pcs. & 82,528 & 35,305 & 132,295 & 78,485 \\
\hline Denied entry to foreign citizens and stateless persons, pers. & 86,240 & 38,270 & 146,933 & 76,757 \\
\hline Expelled and deported, pers. & 5,822 & 5,274 & 16,353 & 14,826 \\
\hline Issued work permits, pcs. & 42,177 & 15,752 & 111,849 & 56,925 \\
\hline Work permits for highly skilled and qualified personnel, pcs. & 1,918 & 1,829 & 7,403 & 5,052 \\
\hline Issued patents, pcs. & 68,157 & 7,058 & 224,108 & 79,730 \\
\hline Money sent to budget, mln.rub. & $3,001.4$ & $1,901.6$ & $5,972.8$ & $4,582.7$ \\
\hline including patents, mln.rub. & 637.7 & 763.5 & $1,594.8$ & $1,399.2$ \\
\hline Residence permits and temporary residence permits issued, pcs. & 11,492 & 21,060 & 25,398 & 51,863 \\
\hline
\end{tabular}

Source: FMS, 2015

The data shows a sharp reduction (almost threefold) in patents issued, while maintaining the amounts received in exchange (-12.3\%). At the same time a twice more temporary residence permits were issued, which confirms the version of the transition of labor migration in part on an illegal basis. Yes, on the one hand, the measures taken will help attract work force of an appropriate quality of the work and services, but on the other, this is again facilitates illegal labor activities and exported of funds away from the tax base.

Thus, migration policy should be developed and implemented in terms of a strategic approach, both at the level of the federal government, and at the level of the Russian Federation, with the main provisions and principles of the demographic policy. In addition, the documents in the field of migration should take into account issues to prevent the negative impact of migration on the national security system and provide opportunities for sustainable socio-economic development.

Uptodate, there are developed and put into action many important policy documents in the field of regulation of migration processes in Russia, all of which represent a system of views on the content, principles and main activities of the Russian Federation in the field of migration. First raised the issue of integration of migrants into Russian society and their adaptation in the host community. From the national security point of view, this issue is particularly relevant. It is important to integrate migrants into the social and cultural environment, to eliminate the cultural distance and reduce tensions between migrants and the local population. However, despite the array of legal documents, immigration law requires further development in the interests of national security of Russia. Considerable attention must be given to the ongoing evaluation of migration processes, their relation to the socio-economic situation and problems of national security.

\section{Conclusion}

The contemporary conditions have formed the need for a set of parameters, criteria and indicators of intersection of migration with the basic elements of the national security through the prism of social and economic processes. This approach to the assessment of the migration situation will enable the development of strategic documents that would consider not only social problems of migrants per se, their economic security, but also to formulate goals and objectives, interconnected with various elements of national security. The parameters must be measured by the change in status and quantitative assessments (universally used). New criteria values of these parameters should be introduced (e.g., maximum and minimum number of foreign nationals employed in various sectors of the economy) as well as indicators characterizing the positive and negative impact of migration on the elements of national security. For example, an indicator of increasing shadow employment may be the exceeding numbers of foreign nationals who entered the country with a private purose over the number of those who have claimed employment as the main purpose of arrival. This set of parameters, criteria and indicators linking the economic, social, and public processes with the processes of security can be the basis of formation of such a migration policy. The implementation of this complex approach will not only contribute 
to the development and use of human and social capital of migrants and their integration into the host society, but can also best protect the country from possible risks and threats to its security.

By studing the changes in the indicators introduced to the evaluation process data, the state authorities can stop focusing on the existing threats and challenges, but develop and implement preventive measures, that is, to prevent threats and prevent the formation of negative calls for the national security.

\section{References}

Adamson, F. (2006). Crossing Borders: International Migration and National Security. International Security, 31 (1), 165-199.

Caviedes, A. (2006). Cracks in fortress Europe? How sectoral needs shape labor migration policy. Ph.D. Thesis, The University of Wisconsin, Madison.

Collet, E. (2014). Outlook on migration in Europe in 2015. Migration policy practice, 4 (5), 21-26.

Dovgopol, E. (2009). National security and illegal migration in Russia. National Security, 1, 88-98.

FMS (2015) [Online] Available: http://www.fms.gov.ru/about/statistics/data/details/54893/ (January 21, 2015). [in Russian]

Kasnauskiene, G., \& Vebraite, L. (2014). The Impact of Migration on Lithuanian Economy in an Ageing Society Context. International Journal of Business and Management, 2 (4), 31-42.

Kulyamina, O., \& Maloletko, A. (2012). Use of the resource potential of the informal sector of the tourism industry. Monograph. Moscow: Publisher Stepanenko.

Kurgan, E.A., \& Anfimova, M.I. (2013). Approaches to enhance the national security of the CIS member states. Business-in-law. Economics and Law Journal, 5, 286-291.

McGregor, E., \& Siegel, M. (2013). Social Media and Migration Research. Unu-Merit Working Paper Series.

Mirilovic, N. (2009). Regime type, security and the politics of migration. Ph.D. Thesis, The University of Chicago.

Rosbalt. [Online] Available: http://m.rosbalt.ru/moscow/2014/10/31/1333449.html (January 21, 2015). [in Russian]

Rossiysk newspaper № 6302(30). It is necessary to detain. [Online] Available: http://www.rg.ru/2014/02/10/prestupleniya-site.html (February 2, 2015). [in Russian]

Rosstat. Rosstat [Online] Available: http://www.gks.ru/free_doc/new_site/population/trud/migrac/mtm_2012.htm_(January 20, 2015).

Stepanov, A. (2014). Security, national security and immigration security, national migration policy: an analysis of the definitions, the ratio categories. Bulletin of the Institute. Vologda Univ Volog. Inst rights and economical. FSIN Russia, 2 (26), 75-78.

Swing, L. W. (2014). Outlook on global migration policy challenges in 2015. Migration policy practice, 4(5), 5-7

Torrado, P., \& Lylian, M. (2008). Impact of migration and political reservations on living standards. Ph.D. Thesis, Boston University.

Vakulenko, H., \& Tsimailo, V. (2011). Accounting for illegal migration: methods and evaluation. Demoskopweekly. Institute of Demography at the National Research University «Higher School of Economics». [Online] Available: http://www.demoscope.ru/ weekly/2011/0479/analit02.php\#_FNR_6 (January 21, 2015).

Vasilyeva, A. (2014). Assessing the impact of migration on the safety of socio-economic development of regions of Russia. Basic Research, 6-1, 118-122.

Vdovina, O. (2011). Migration and Security: structure interaction. Sociology structure interaction in the modern world: science, education, creativity, 3, 208-211.

Vzglyad. Business newspaper. In SK called real crime rate among migrants in Moscow. [Online] Available: http://vz.ru/news/2014/1/29/ 670160.html29 (January 29, 2015). [in Russian]

Yudina, T. (2007). Migration: glossary of key terms: Proc. allowance. Moscow: Publishing RSSU, Academic Project.

Zayonchkovskaya, J. Migration in modern Russia. Russian Council on International Affairs. [Online] Available: http://russiancouncil.ru/ inner/?id_4=1714\#top (January 19, 2015). 